Dr Gojko Jovanovié, potpukovnik, dipl. inž.

Mr Stjepan Vidačić, kapetan I kíase, dipl. inž.

\section{Poboljšana verzija softvera za automatizirano planiranje vojnog putnog saobraćaja}

\section{Uvod}

Praktična primjena softvera za automatizirano planiranje vojnog putnog saobraćaja (osnovna verzija), koji je razvijen na Saobraćajnom smjeru VVTS̆ u Applesoft BASIC-u na računaru Apple IIe [1], na nekoliko posljednjih vojnih vježbi (ROMANIJA '88, CESMA '89 i drugim), potvrdila je njegovu praktičnu vrijednost.

Ta vrijednost se prvenstveno ogleda u automatizaciji procesa izrade osnovnih planskih dokumenata, koji se izraôju pri planiranju kretanja vojnih motoriziranih kolona (plan marša, grafikon marša i vremenski kontrolnik), čme se mnogostruko skraćuje vrijeme koje organ SbSi troši na ovu aktivnost.

Međutim, praksa je ukazala i na neke nedostatke osnovne verzije navedenog softvera:

1) nepraktičan interaktivni način formiranja baze podataka o putnoj mreži iz aplikacijskog programa i složen postupak proširivanja i ažuriranja baze podataka;

2) ograničena upotrebna vrijednost softvera, zbog malog kapaciteta radne memorije racunara Apple IIe (64 KB), za koji je razvijena osnovna verzija softvera;

3) neadekvatno riješen problem promjene mjerodavnog vozila;
4) mala upotrebna vrijednost grafikona marša, zbog niske rezolucije grafike računara Apple IIe;

5) neriješen problem zaustavljanja kolone u toku kretanja (zastanci, odmori i sl.), i dr.

S obzirom na navedena ograničenja računara Apple IIe, daljnji razvoj osnovne verzije softvera na ovom računaru nije imao perspektivu.

Zbog toga je nova verzija softvera razrađena na perspektivnom personalnom računaru Macintosh, u strukturalnoj verziji jezika BASIC pod nazivom ZBASIC, koji je kompatibilan sa standardnim Microsoft BASIC-om i kao takav pruža značajne mogućnosti za daljnji razvoj softvera za automatizirano planiranje vojnog putnog saobraćaja.

U novoj verziji softvera otklonjeni su svi navedeni nedostaci.

Time je učinjen značajan pomak u pravcu povećanja tupotrebne vrijednosti softvera za automatizirano planiranje vojnog putnog saobraćaja.

\section{Softver za automatizirano planiranje vojnog putnog saobraćaja}

Nova verzija softvera za automatizirano planiranje vojnog putnog saobraćaja je realizirana u obliku paketa programa koji se sastoji od vodeceg 
programa PLAVS (sl. 1), iz kojeg se pokreće osnovni program TRANS (formiranje operativne baze podataka 0 putnoj mreži) i program PLAN (planiranje kretanja), koji su detaljnije objašnjeni u narednoin tekstu.

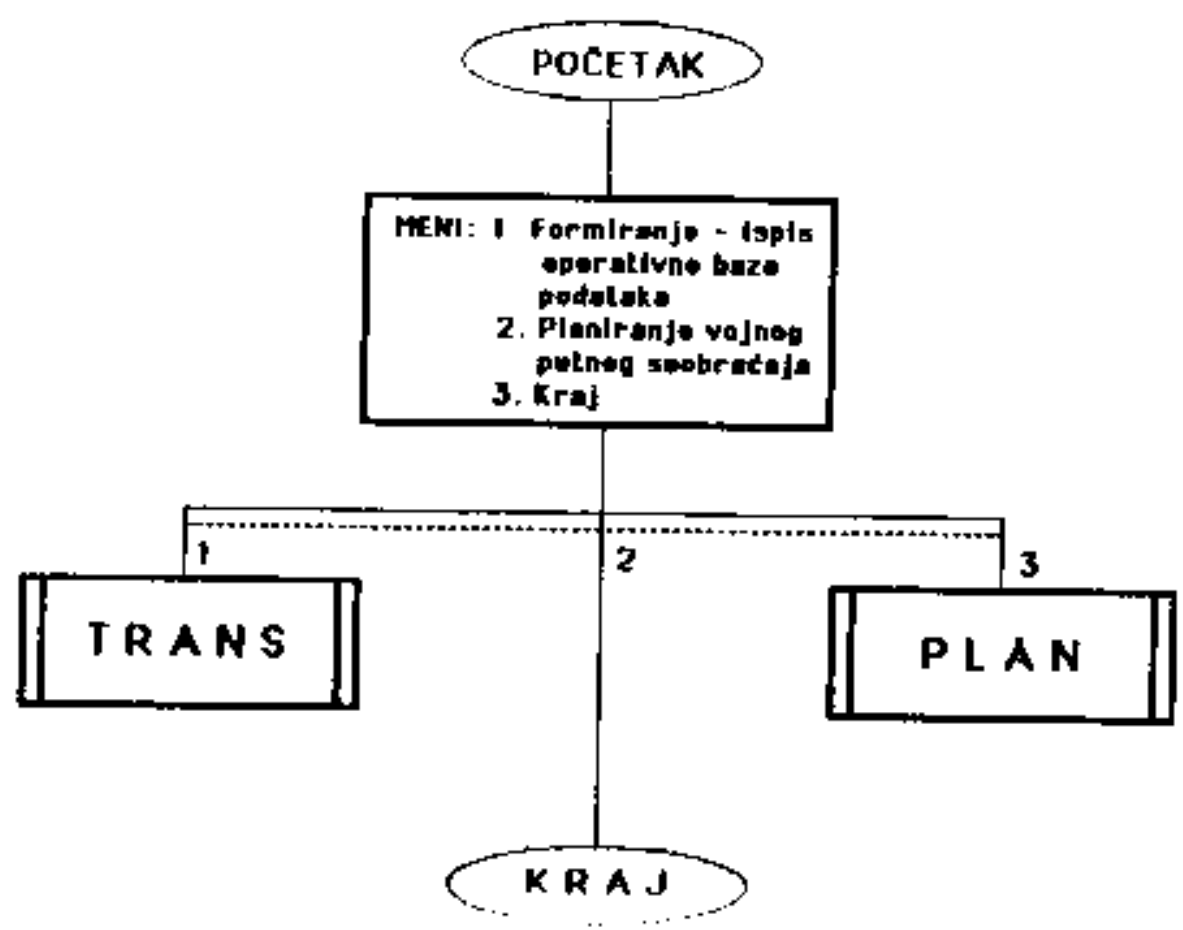

Sl. I Globalni blok-dijagram vodećeg programa PLAVS

Algoritamska verzija softvera pohranjena je u binarnom obliku i izvršava se kao čisti mašinski program, što omogućava maksimalnu brzinu rada, bez upotrebe sistema jezika ZBASIC. opéu i operativnu bazu podataka. Op ća baza podataka je formirana u pro fesionalnom sistemu $\mathrm{za}$ rad $\mathrm{s}$ bazam podataka FILEMAKER, koji ima velik mogućnosti za formiranje, proširiva nje, ažuriranje, pretraživanje i automatsko generiranje tekst datoteka, $n$ osnovtı datoteke baze podataka.

Osnovna struktura datoteke opć baze podataka o putnoj mreži prikaza. na je na slici 2 ( $\mathrm{L}$ - dužina dionic [km], A - maksimalni uzdužni nagi puta $[\% / v], Z$ - vrsta kolovoznog zas tora [1 - dobar asfalt, 2 - los asfalti 3 - dobar tucanik, 4 - loš tucanik, - zemljani put]).

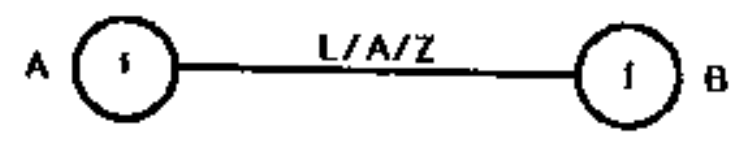

Sl. 3 Model dionice puta putne mreže

Podaci koji se unose u opću datoteku podataka uzimaju se sa putne karte. Radi lakšeg očitavanja podataka si karte konstruira se pomoćni model putne nireže prikazan na slici 3 .

Taj model putne mreže služi za di. rektno očitavanje i unošenje podataka u bazu podataka.

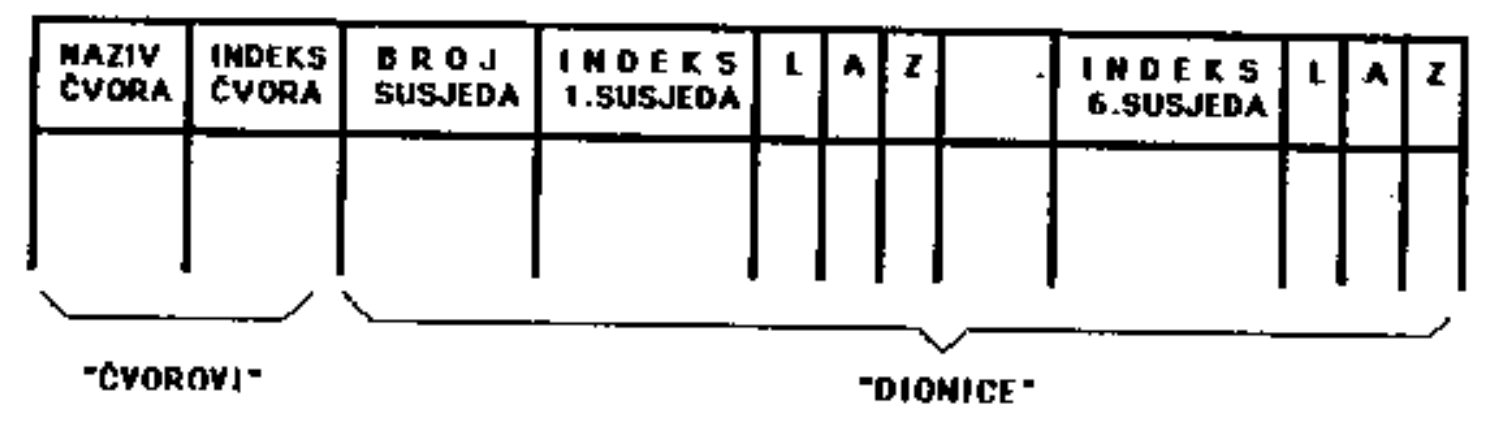

Sl. 2 Struktura datoteke apce baze podataka o puthoj mreži

Ova verzija na računaru Macintosh sa $512 \mathrm{~Kb}$ radne memorije može raditi s bazom podataka o mreži puteva, koja ima do 1500 čvorova (raskrsnica - naseljenih mjesta).

\section{Baza podataka o putnoj mreži}

Bazal podataka o putnoj mreži čini osnovu za automatizirano planiranje vojnog putnog saobraćaja. Dijeli se na
Pri konstruiranju pomoćnog modele putne mreže važno je pravilno definiranje dionice puta, pri čemu je nužno da dionica na čitavoj svojoj dužini ima približno iste karakteristike. To se prvenstveno odnosi na uzdužni nagib puta i vistu kolovoznog zastora.

Iz sistema FILEMAKER se automatski formiraju dvije tekst datoteke, od kojih datoteka CVOROVI $\mathrm{I}_{i}$ sadrži prva dva, a datoteka DIONICE ostala 
2) definiranje strukture datoteke opće baze podataka o putnoj mreži u sistemu FILEMAKER (sl. 2);

3) unošenje podataka sa pomoćnog modela putne mreže u bazu podataka;

4) formiranje tekst-datoteka CVOROVI $_{\mathrm{i}}$ I DIONICE $_{\mathrm{i}}$ (sl. 2) iz sistema FILEMAKER;

5) definiranje strukture datoteke baze podataka o tipovima vozila (sl. 6);

6) unošenje podataka o tipovima vozila u bazu podataka;

7) formiranje tekst-datoteke TIPMV (sl. 2) o tipovima yozila iz sistema FILEMAKER;

8) formiranje datoteke SUS $S_{i}$ operativne baze podataka pomoću programa TRANS.

Prvi korak zahtijeva najviše vremena i od njegove realizacije direktno zavisi kvalitet operativne baze podataka.

Drugi korak je jednostavan i zahtijeva minimalno vrijeme.

Treći, četvrti i osmi korak se ponavljaju pri svakom ažuriranju ili proširivanju opće baze pođataka o putnoj mreži.

Treći korak se može realizirati postepeno, a zbog jednostavnosti sistema FILEMAKER podaci se unose jednostavno i brzo, uz neograničenu mogućnost pretraživanja, provjere $i$ ispravki unesenih podataka.

Cetvrti korak se realizira automatski, a vrijeme potrebno za njegovu realizaciju je proporcionalno broju čvorova u mreži

Peti, šesti i sedmi korak se ponavljaju samo pri formiranju ili proširivanju baze podataka o tipovima vozila.

Osmi korak se realizira gotovo jednako brzo kao i cetvrti, zbog izvršavanja programa TRANS u mašinskom jeziku.

Opisana metodika formiranja operativne baze podataka je, u suštini, jednostavna i nužno je da je korisnik softvera poznaje.

\section{Automatizirano planiranje vojnog putnog saobraćaja}

Osnovni dokumenti koji se izrađuju pri planiranju kretanja izrađuju se pomoću programa PLAN, čiji je globalni blok-dijagram prikazan na slici 7 .

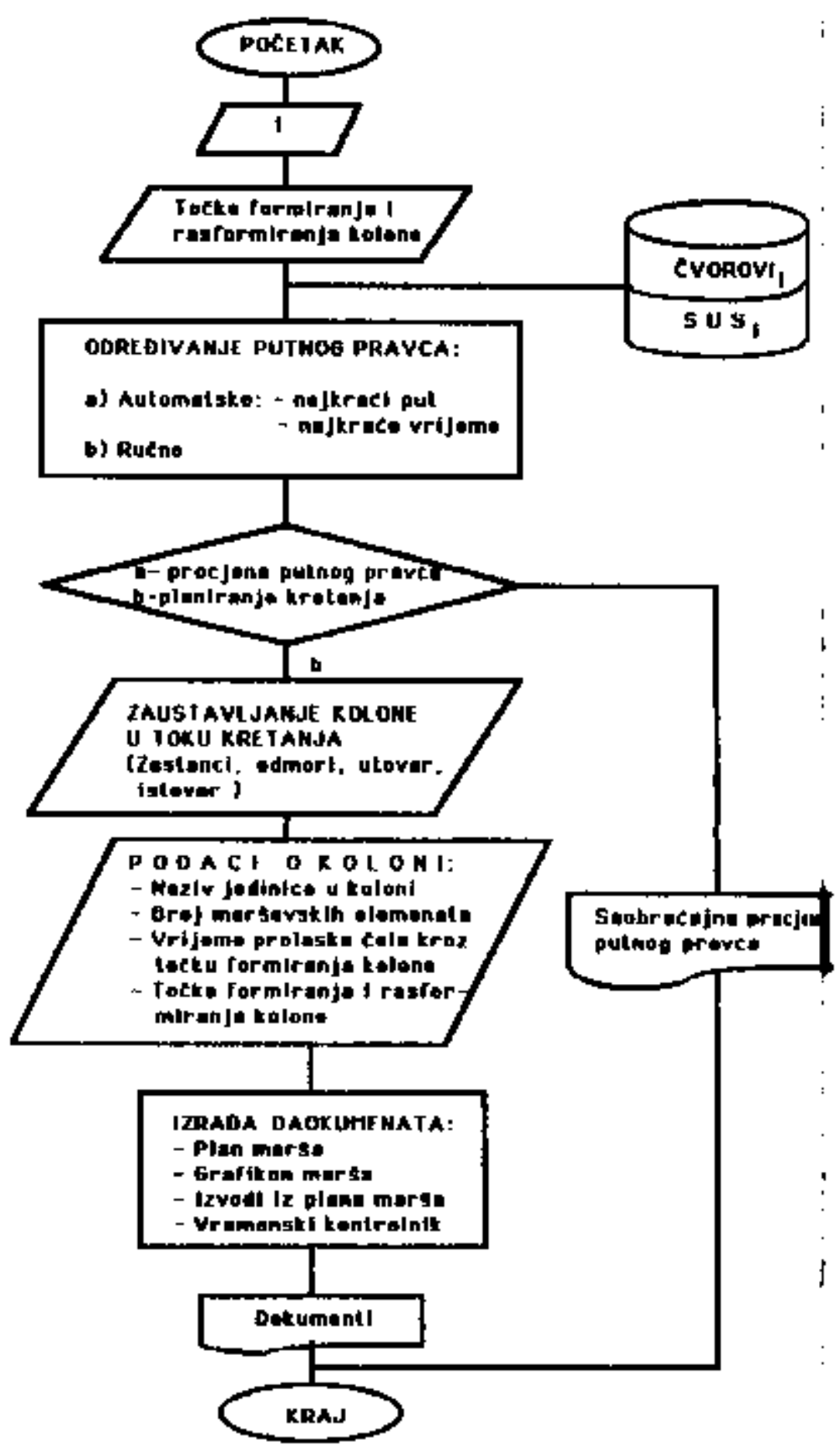

St. 7 Globalnt blok-dijagram programa PLAs:

Nova verzija softvera se, u odnosis na osnovnu verziju [1], bitno razlikł je po:

- mogućnosti uvođenja prekida kretanja kolone zbog zastanaka, odmo ra, utovara, istovara, i sl.;

- novom izgledu tabele plana mar. ร̌a,

(sl. 8). 
ODOBRA VAM:

Obrazac SbS1

VOJNA TAJNA

Povjerljivo

Plan marša kolone

na dan

\begin{tabular}{|c|c|c|c|c|c|c|c|c|}
\hline \multirow{3}{*}{ Naziv mjesta } & \multirow{3}{*}{$\begin{array}{c}\text { Kilo- } \\
\text { metra- } \\
\text { ža }[\mathrm{km}]\end{array}$} & \multirow{3}{*}{$\begin{array}{l}\text { Dionix. } \\
\text { brzina } \\
{[\mathrm{km} / \mathrm{h}]}\end{array}$} & \multicolumn{6}{|c|}{ Vrijeme prolaza [h] } \\
\hline & & & \multicolumn{2}{|c|}{ 1. ES } & \multicolumn{2}{|c|}{ 2. ES } & \multicolumn{2}{|c|}{ 3. ES } \\
\hline & & & celo & začelje & čelo & začelje & celo & začelje \\
\hline Đakovo & 0 & 0 & 18.45 & 18.51 & 18.55 & 19.01 & 19.05 & 19.11 \\
\hline Vrpolje & 12 & 30 & 19.09 & 19.15 & 19.19 & 19.25 & 19.29 & 19.35 \\
\hline Mjes. zast. -1 & 15 & 27 & 19.15 & 19.21 & 19.25 & 19.31 & 19.35 & 19.41 \\
\hline \multicolumn{9}{|c|}{ Utovar $=55 \mathrm{~min}$} \\
\hline Garcin & 28 & 27 & 20.38 & 20.44 & 20.48 & 20.54 & 20.58 & 21.04 \\
\hline Slav. Brod & 42 & 28 & 21.08 & 21.14 & 21.18 & 21.24 & 21.28 & 21.34 \\
\hline B. Stupnik & 59 & 19 & 22.00 & 22.06 & 22.10 & 22.16 & 22.20 & 22.26 \\
\hline \multicolumn{9}{|c|}{$\mathrm{Zastanak}=15 \mathrm{~min}$} \\
\hline Luzani & 69 & 28 & 22.21 & 22.27 & 22.31 & 22.37 & 22.41 & 22.47 \\
\hline Batrina & 74 & 30 & 22.31 & 22.37 & 22.41 & 22.47 & 22.51 & 22.57 \\
\hline N. Gradiška & 98 & 22 & 23.35 & 23.41 & 23.45 & 23.51 & 23.55 & .01 \\
\hline
\end{tabular}

Istovar $=45 \mathrm{~min}$.

Okucani

112

30

.48

.54

.58

1.04

1.08

1.14

I Z R A D I O: 
Obrazac SbSt

ODOBRAYAM:

YOJNA TANNA

Povjerljivo

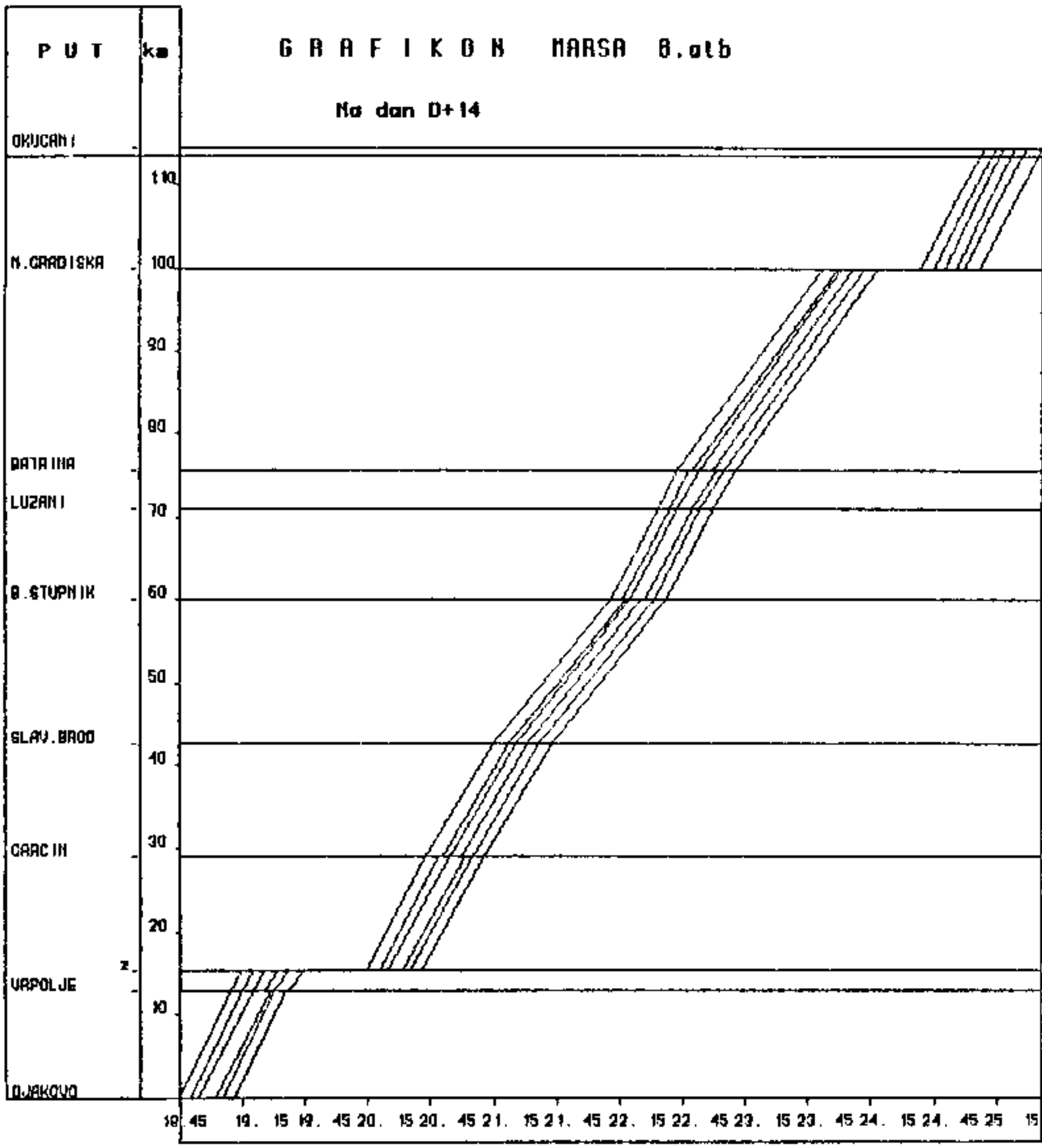

Urijene( h)

|2RADIO:

Sl. 8 Primjer grafikona marša kolone 
Na tabeli marša prikazuje se potpuna dinamika kretanja kolone, a grafikon marša je njen vjerni grafički prikaz, koji se crta na formatu papira A4 i ima punu upotrebnu vrijednost.

Korišćenje programa PLAN je za operatera veoma jednostavno $i$ on se $u$ procesu planiranja može pokretati neograničeni broj puta.

Jedino u slučaju potrebe korekcije datoteka operativne baze podataka o putnoj mreži SUS $i$ i CVOROVI, potrebno je prethodno izvršiti postupak ažuriranja opće baze podataka o putnoj mreži, koji je opisan u odeljku »Baza podataka o putnoj mreži .

\section{Zaključak}

Najnovija verzija softvera za automatizirano planiranje vojnog putnog saobraćaja prezentirana u ovom radu, predstavlja značajan doprinos rješavanju problema automatizacije ovog složnog procesa, što je već potvrđeno u praksi, na vježbi ČESMA 88/89.
Implementacija na personalni računar Macintosh $u$ strukturainoj verziji jezika BASIC pod nazivom ZBASIC, koja je kompatibilna sa standardnim Microsoft BASIC-om, omogućava dalji razvoj ovog softvera i jednostavnu implementaciju i na cruge tipove personalnih računara.

Оріsала metodika formiranja baze podataka o putnoj mreži omogućava nezavisnost između opće i operativne baze podataka i osigurava potrebnu elastičnost baze zbog mogućih promjena na putnoj mreži, nezavisno od softvera za automatizirano planiranje vojnog putnog saobracaja.

$\mathrm{Na}$ taj nacin je softver u potpunosti rasterećen od problema korekcije baze podataka o putnoj mreži i otvoren za dalji razvoj mogućnosti vezanih za planiranje vojnog putnog saobraćaja.

Naredni korak u razvoju softvera je konačno rješenje izlaznih dokumenata i automatizacija procesa izrade putnog grafikona. 